Acta Crystallographica Section D

Biological

Crystallography

ISSN 0907-4449

\title{
Cloning, purification and characterization of the 6-phospho-3-hexulose isomerase YckF from Bacillus subtilis
}

The enzyme 6-phospho-3-hexulose isomerase (YckF) from Bacillus subtilis has been prepared and crystallized in a form suitable for Received 29 January 2001 Accepted 4 May 2001 $\mathrm{X}$-ray crystallographic analysis. Crystals were grown by the hangingdrop method at $291 \mathrm{~K}$ using polyethylene glycol 2000 monomethylether as precipitant. They diffract beyond $1.7 \AA$ using an in-house $\mathrm{Cu} K \alpha$ source and belong to either space group $P 6_{5} 22$ or $P 6_{1} 22$, with unit-cell parameters $a=b=72.4, c=241.2 \AA$, and have two molecules of $\mathrm{YckF}$ in the asymmetric unit.

${ }^{\mathrm{a}}$ School of Sciences, University of Sunderland, Sunderland SR1 3SD, England, and ${ }^{\mathbf{b}}$ Structural Biology Laboratory, Department of Chemistry, University of York, Heslington, York YO10 5DD, England

\begin{abstract}
† Present address: Department of Biological and Nutritional Sciences, University of Newcastle, Newcastle upon Tyne NE1 7RU, England. ₹ Present address: School of Applied and Molecular Sciences, University of Northumbria at Newcastle, Newcastle upon Tyne NE1 8ST, England.
\end{abstract}

Correspondence e-mail: gary.black@unn.ac.uk
C 2001 International Union of Crystallography Printed in Denmark - all rights reserved

\section{Introduction}

6-Phospho-3-hexulose isomerase (PHI) catalyses the isomerization of D-arabino-3-hexulose-6-phosphate to D-fructose-6-phosphate, as illustrated in Fig. 1. PHI is a key enzyme in the fixation of carbon, in the form of formaldehyde, by methylotrophic bacteria. This process is part of the ribulose monophosphate (RuMP) pathway, the key function of which is the condensation of formaldehyde with ribulose-5phosphate by 3-hexulose-6-phosphate synthase (HPS) to form D-arabino-3-hexulose-6-phosphate, which in turn is isomerized by PHI to fructose-6-phosphate. The subsequent metabolism of fructose-6-phosphate leads to the regeneration of the pentose phosphate acceptor and the net production of triose phosphate (Strøm et al., 1974). Until recently, it was believed that such enzyme systems were restricted solely to methylotrophic organisms. However, the recent explosion of information arising from genome-sequencing projects has led to the identification of similar genes in nonmethylotrophs such as B. subtilis (Kunst et al., 1997; Reizer et al., 1997; Yasueda et al., 1999). Investigation at the gene-expression level suggests that in this organism these gene products play a specific role in detoxification. For example, when B. subtilis was cultured in the presence of formaldehyde, the expression of PHI (i.e. YckF) and HPS (i.e. YckG) was induced. The observation that methanol, formate and methylamine did not elicit a similar response and the fact that induction of YckF and YckG expression was dependent on another gene, $y c k H$, strongly suggest that these three genes function as a specific detoxification system for formaldehyde in this organism (Yasueda et al., 1999).

The $y c k F$ gene from $B$. subtilis consists of a $558 \mathrm{bp}$ open reading frame (ORF) which encodes a $19.96 \mathrm{kDa}$ protein (Kunst et al., 1997). YckF exhibits significant homology (34 and $37 \%$, respectively) with functional PHIs from the obligate methylotrophic bacterium Methylomonas aminofaciens 77a (Sakai et al., 1999) and the facultative methylotrophic bacterium Mycobacterium gastri MB19 (Mitsui et al., 2000; Fig. 2). YckF also shares $22.8 \%$ identity with the putative CP0226 gene of Chlamydophila pneumoniae AR39 and three putative genes from Haemophilus influenzae, HI0143 (18\%), HI1678 (18.6\%) and HI0754 (14.8\%). Similarity (16.2\%) also exists to a fructose-6-phosphate aminotransferase gene, glmS, from B. subtilis. Although PHI enzymes have been purified and characterized from a range of organisms (Beardsmore et al., 1982; Ferenci et al., 1974; Kato et al., 1977; Sakai et al., 1999; Mitsui et al., 2000), little is known about their catalytic mechanism. Metal-ion dependency is a common feature amongst previously characterized sugar isomerases, with cobalt, magnesium and manganese predominantly implicated (Watt, 1998). However, the PHI from Methylococcus capsulatus has been shown to be fully active in the absence of cations and to be inhibited by various divalent cations (Ferenci et al., 1974). However, it is currently unknown whether YckF is active in the absence of cations. Despite the importance of PHI in terms of carbon fixation, detoxification and its potential in biotransformation applications, little is known about its structure or function. In this paper, we present the cloning and overexpression of the $y c k F$ gene using an Escherichia coli expression system, together with its purification, crystallization and preliminary $\mathrm{X}$-ray diffraction analysis.

\section{Experimental}

\subsection{Cloning, expression and purification}

PfuTurbo DNA polymerase (Stratagene) and the oligonucleotide primers 5'-CATAT- 
GAAAACGACTGAATACG-3' and $5^{\prime}$ GGATCCCTATTCAAGGTTTGCGTG-3' were used to amplify the $y c k F$ gene from B. subtilis 168 (ATCC 23857) genomic DNA. This fragment encoded the $y c k F$ gene flanked by $N d e$ I and BamHI restriction sites. The 567 bp fragment was cloned using the A-tailing procedure for cloning blunt-ended PCR fragments into pGEMT-Easy (Promega). The insert was subcloned into the expression vector pET28a (Novogen) on an NdeI/BamHI restriction fragment, generating the plasmid pBSISO1. The recombinant plasmid was transformed into $E$. coli strain BL21 (DE3), which had been made competent by the method of Hanahan (1983). The transformants were cultured on LB agar supplemented with $50 \mu \mathrm{g} \mathrm{ml}^{-1}$ kanamycin at $310 \mathrm{~K}$. Cultures for induction were inoculated from a $5 \mathrm{ml} 16 \mathrm{~h}$ culture and grown in LB supplemented with $50 \mu \mathrm{g} \mathrm{ml}^{-1}$ kanamycin. Isopropyl-thio- $\beta$-D-galactoside was added to a final concentration of $1 \mathrm{~m} M$ when the optical density at $600 \mathrm{~nm}$ had reached 0.7, after which incubation was continued for a further $16 \mathrm{~h}$ at a reduced temperature of $295 \mathrm{~K}$. The bacteria were harvested by centrifugation, resuspended in

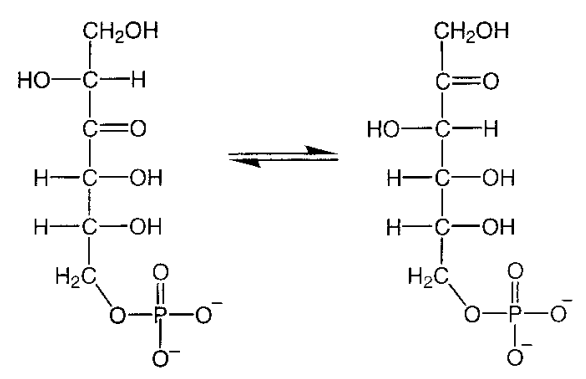

Figure 1

6-Phospho-3-hexulose isomerase catalyses the isomerization of D-arabino-3-hexulose-6-phosphate to D-fructose-6-phosphate.
$20 \mathrm{mM} \mathrm{Na} \mathrm{HPO}_{4}$ buffer $\mathrm{pH} 7.4$ containing $0.5 \mathrm{M} \mathrm{NaCl}$ and $10 \mathrm{~m} M$ imidazole and sonicated on ice for a total of 1 min using a $10 \mathrm{~s}$ on and $10 \mathrm{~s}$ off cycle. Cell debris was removed by centrifugation at $30000 \mathrm{~g}$ for $30 \mathrm{~min}$. The crude extract was loaded onto a PD-10 column (Pharmacia Biotech) containing a $2 \mathrm{ml}$ bed volume of nickelcharged Fast Flow Chelating Sepharose. Purification was achieved as described by the manufacturer, except for the inclusion of two additional washing steps with $100 \mathrm{mM}$ imidazole. The eluted protein was buffer exchanged into $20 \mathrm{~m} M$ Na HEPES buffer pH 7.4 using a Sephadex PD-10 G-25M column (Pharmacia Biotech). The purity of YckF was assessed by SDS-PAGE analysis. The purified protein was concentrated using a $10 \mathrm{kDa}$ molecular-weight cutoff centrifugation membrane (Amicon).

\subsection{PHI assay}

To determine whether recombinant YckF was active, it was assayed according to the method of Arfman et al. (1990) with modifications as described by Yasueda et al. (1999). This multi-enzyme linked assay features ribose-5-phosphate conversion to ribulose-5-phosphate by ribose phosphate isomerase. The product of this first reaction is then combined with formaldehyde by 3-hexulose-6-phosphate synthase, generating D-arabino-3-hexulose-6-phosphate, the substrate for YckF. The product of YckF, fructose-6-phosphate, then undergoes isomerization by phosphoglucose isomerase, yielding glucose-6-phosphate, which is finally converted to 6-phosphoglucono- $\delta$ lactone by glucose-6-phosphate dehydrogenase, leading to the production of $\mathrm{NADPH}$, which is followed at $340 \mathrm{~nm}$.

\begin{abstract}
B. subtilis
M. gastri

M. aminofaciens

-..........-MKTTEYVAEILNELHNSAAYI SNEEADOLADHILSSFOIFTAGAG MTOAAEADGAVKVVGDDITNNLSLVRDEVADTAAKVDPEQVAVLARQIVQPGRVFVAGAG 60 -------------MNKYQELVVSKLTNVINNTAEGYDDKILSLVDAAGRTFIGGAG 43

B. subtilis

M. gastri

M. aminofaciens

B. subtilis

M. gastri

M. aminofaciens

B. subtilis

M. gastri

M. aminofaciens

RSGLMAKSFAMRLMHMGFNAH IVGEILTPPLAEGDLVIIGSGSGETKSLIHTAAKAKSLH 105 RSGLVLRMAAMRLMHFGLTVHVAGDTTTPAISAGDLLLVASGSGTTSGVVKSAETAKKAG 120 RSLLVSRFFAMRLVHAGYQVSMVGEVVTPSIQAGDLFIVISGSGSTETLMPLVKKAKSQG 103

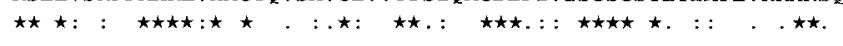

GIVAALTINPESSIGKQADLIIRMPGSPKDQSNGSYKTIQPMGSLFEQTLLLFYDAVILK 165 ARIAAFTTNPDSPLAGLADAVVIIPAAQKT-DHGSHISRQYAGSLFEQVLFVTTEAVFQS 179 AKIIVISMKAQSPMAELADLVVPVGGNDANAFDKTHG--MPMGTIFELSTLWFLEATIAK 161

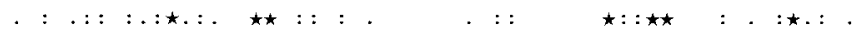

LME - .............. KKGLDSETMFTHHANLE

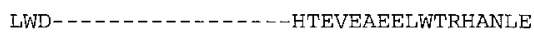

LVDQKGLTEEGMRAIHANLEHTEVEAEELWTRHANLE

$\begin{array}{ll}\star & : \quad::::^{\prime}:: \star: \star \star \star \star \star\end{array}$
\end{abstract}

Figure 2

A ClustalW (1.8) multiple sequence alignment of 6-phospho-3-hexulose isomerases from $B$. subtilis, Mycobacterium gastri and Methylmonas aminofaciens. The position of identical residues (asterisks) and conserved (:) and semi-conserved (.) substitutions are indicated.

\subsection{Crystallization}

Crystals of YckF were grown by vapourphase diffusion using the hanging-drop method in Falcon 3047 multiwell plates at $291 \mathrm{~K}$. The drops comprised an equal volume, 1 or $2 \mu \mathrm{l}$, of YckF at a concentration of $20 \mathrm{mg} \mathrm{ml}^{-1}$ mixed with reservoir solution. Crystals of YckF appeared in numerous conditions of the crystallization screen as described by Brzozowski \& Walton (2001) after only a few hours. These initial conditions were optimized by the addition of 10 or $20 \%(v / v)$ of either glycerol, 2-methyl-2,4pentandiol (MPD) or ethylene glycol and reducing the protein concentration to $10 \mathrm{mg} \mathrm{ml}^{-1}$. When the reservoir solution comprised $0.8 M$ sodium formate, $1 \mathrm{~m} M$ EDTA, $25 \%(w / v)$ polyethylene glycol 2000 monomethylether and $10 \%(v / v)$ MPD in $20 \mathrm{~m} M$ Na HEPES buffer $\mathrm{pH} 7.4$, hexagonal crystals appeared after $24 \mathrm{~h}$ and had approximate dimensions of $0.2 \times 0.2 \times$ $0.1 \mathrm{~mm}$ (Fig. 3). This buffer solution was also a cryoprotectant, enabling crystals to be mounted directly into a rayon-fibre loop and placed into a stream of $\mathrm{N}_{2}$ gas at $120 \mathrm{~K}$.

\subsection{Data collection and processing}

Native X-ray diffraction data were collected in the home laboratory from a single crystal at $120 \mathrm{~K}$ using a $345 \mathrm{~mm}$ MAR Research imaging-plate detector on a Rigaku rotating-anode RU-200 X-ray generator with a $\mathrm{Cu}$ target operating at $50 \mathrm{kV}$ and $100 \mathrm{~mA}$ with the use of focusing X-ray optics (MSC). $40.4^{\circ}$ of data to a resolution of $2.6 \AA$ were collected with an oscillation range of $0.2^{\circ}$ and an exposure time of $10 \mathrm{~min}$ per image. Data were processed and reduced using the DENZO and SCALEPACK programs (Otwinowski \& Minor, 1997).

\section{Results and discussion}

Purified YckF was apparently pure as judged by SDS-PAGE analysis and ran as a single well defined band when conducting non-denaturing polyacrylamide gel electrophoresis (data not shown). MALDI-TOF mass-spectrometric analysis indicated that recombinant YckF had a molecular mass of $22.16 \mathrm{kDa}$, consistent with the predicted value, $22.13 \mathrm{kDa}$, which includes the $\mathrm{N}$ terminal polyhistidine tag. The purified protein was very stable and could be stored at $277 \mathrm{~K}$ at a protein concentration of $20 \mathrm{mg} \mathrm{ml}^{-1}$ in $20 \mathrm{~m} M$ Na HEPES buffer $\mathrm{pH}$ 7.4. To determine whether YckF was active, it was assayed, as described in $\$ 2.2$, by measuring the production of NADPH at 
$340 \mathrm{~nm}$. Recombinant YckF had a specific activity of $193 \mu \mathrm{mol}$ of $\mathrm{NADP}^{+}$reduced per minute per milligram of pure enzyme. Crystals of YckF belong to space group $P 6_{5} 22$ or $P 6_{1} 22$, with unit-cell parameters $a=b=72.4, c=241.2 \AA$, and most likely have two protein molecules in the asymmetric unit. Crystals of YckF diffracted very strongly in the home laboratory, but the resolution of such data was constrained to $2.6 \AA$ owing to the long $c$ axis. 202840 observations were merged to give 12384 unique reflections, with an $R_{\text {merge }}$ $\left(\sum_{h k l} \sum_{i}\left|I_{h k l}-\left\langle I_{h k l}\right\rangle\right| / \sum_{h k l} \sum_{i} I_{h k l}\right)$ of 0.019 , a mean $I / \sigma(I)$ of 48.9 , a multiplicity of observation of 4.2 and a completeness of $94 \%$ in the $12-2.6 \AA$ resolution range. The data were very strong, with an $R_{\text {merge }}$ of 0.027 and a mean $I / \sigma(I)$ of 32.4 and a multiplicity of observation of 4.4 in the outer resolution shell (2.69-2.6 ̊). Assuming that there are two molecules in the asymmetric unit, the crystal packing density was determined to be $2.07 \AA^{3} \mathrm{Da}^{-1}$, which corresponds to a solvent content of $40.2 \%$ (Matthews, 1968). Alternatively, though less likely, one molecule in the asymmetric unit

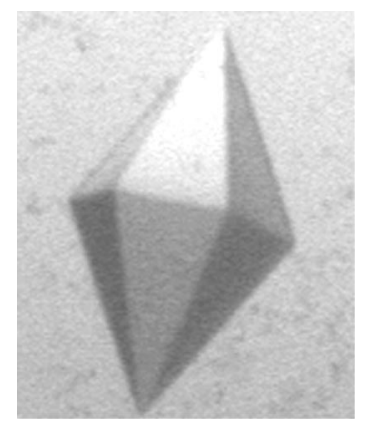

Figure 3

A single crystal of YckF from B. subtilis. This hexagonal crystal with dimensions $0.1 \times 0.1 \times$ $0.2 \mathrm{~mm}$ was obtained using $20 \mathrm{~m} M$ Na HEPES buffer $\mathrm{pH} 7.4$ containing $0.8 \mathrm{M}$ sodium formate, $1 \mathrm{mM}$ EDTA, 25\% $(w / v)$ polyethylene glycol 2000 monomethylether and $10 \%(v / v)$ MPD. corresponds to a density and solvent content of $4.15 \AA^{3} \mathrm{Da}^{-1}$ and $70.1 \%$, respectively.

The structure of YckF will allow illumination of the catalytic mechanism and substrate specificity of this important family of proteins and will give an insight into the closely related homologues of unknown function from various pathogenic bacteria such as $H$. influenzae and $C$. pneumoniae. These putative enzymes, although distantly related, appear to possess the same catalytic machinery as YckF from B. subtilis. Structural data will also allow the rational design of catalysts for specific biotransformations using PHI with other RuMP pathway enzymes. Selenomethionine-substituted protein is currently being produced to aid rapid structure determination.

The authors would like to thank the BBSRC Wellcome Trust and EU for financial assistance. GJD is a Royal Society University Research Fellow. Collaboration between the Universities of York and Sunderland was assisted by the provision of a BBSRC Structural Biology Centre award to the York Structural Biology Laboratory.

\section{References}

Arfman, N., Bystrykh, L., Govorukhina, N. I. \& Dijkhuizen, L. (1990). Methods Enzymol. 188, 391-397.

Beardsmore, A. J., Aperghis, P. N. J. \& Quayle, J. R. (1982). J. Gen. Microbiol. 128, 1423-1439.

Brzozowski, A. M. \& Walton, J. (2001). J. Appl. Cryst. 34, 97-101.

Ferenci, T., Strøm, T. \& Quayle, J. R. (1974). Biochem. J. 144, 477-486.

Hanahan, D. (1983). J. Mol. Biol. 166, 557-580

Kato, N., Ohashi, H., Hori, T., Tani, Y. \& Ogata, K. (1977). Agric. Biol. Chem. 41, 1133-1140.

Kunst, F., Ogasawara, N., Moszer, I., Albertini, A. M., Alloni, G., Azevedo, V., Bertero, M. G., Bessieres, P., Bolotin, A., Borchert, S., Borriss, R., Boursier, L., Brans, A., Braun, M., Brignell, S. C., Bron, S., Brouillet, S., Bruschi, C. V., Caldwell, B., Capuano, V., Carter, N. M., Choi,
S. K., Codani, J. J., Connerton, I. F., Cummings, N. J., Daniel, R. A., Denizot, F., Devine, K. M., Dusterhoft, A., Ehrlich, S. D., Emmerson, P. T., Entian, K. D., Errington, J., Fabret, C., Ferrari, E., Foulger, D., Fritz, C., Fujita, M., Fujita, Y., Fuma, S., Galizzi, A., Galleron, N., Ghim, S. Y., Glaser, P., Goffeau, A., Golightly, E. J., Grandi, G., Guiseppi, G., Guy, B. J., Haga, K., Haiech, J., Harwood, C. R., Henaut, A., Hilbert, H., Holsappel, S., Hosono, S., Hullo, M. F., Itaya, M., Jones, L., Joris, B., Karamata, D., Kasahara, Y., KlaerrBlanchard, M., Klein, C., Kobayashi, Y., Koetter, P., Koningstein, G., Krogh, S., Kumano, M., Kurita, K., Lapidus, A., Lardinois, S., Lauber, J., Lazarevic, V., Lee, S. M., Levine, A., Liu, H., Masuda, S., Mauel, C., Medigue, C., Medina, N., Mellado, R. P., Mizuno, M., Moestl, D., Nakai, S., Noback, M., Noone, D., Oreilly, M., Ogawa, K., Ogiwara, A., Oudega, B., Park, S. H., Parro, V., Pohl, T. M., Portetelle, D., Porwollik, S., Prescott, A. M., Presecan, E., Pujic, P., Purnelle, B., Rapoport, G., Rey, M., Reynolds, S., Rieger, M., Rivolta, C., Rocha, E., Roche, B., Rose, M., Sadaie, Y., Sato, T., Scanlan, E., Schleich, S., Schroeter, R., Scoffone, F., Sekiguchi, J., Sekowska, A., Seror, S. J., Serror, P., Shin, B. S., Soldo, B., Sorokin, A., Tacconi, E., Takagi, T., Takahashi, H., Takemaru, K., Takeuchi, M., Tamakoshi, A., Tanaka, T., Terpstra, P., Tognoni, A., Tosato, V., Uchiyama, S., Vandenbol, M., Vannier, F., Vassarotti, A., Viari, A., Wambutt, R., Wedler, E., Wedler, H., Weitzenegger, T., Winters, P., Wipat, A., Yamamoto, H., Yamane, K., Yasumoto, K., Yata, K., Yoshida, K., Yoshikawa, H. F., Zumstein, E., Yoshikawa, H. \& Danchin, A. (1997). Nature (London), 390, 249-256.

Matthews, B. W. (1968). J. Mol. Biol. 33, 491-497.

Mitsui, R., Sakia, Y., Yasueda, H. \& Kato, N. J. (2000). J. Bacteriol. 182, 944-948.

Otwinowski, Z. \& Minor, W. (1997). Methods Enzymol. 276, 307-326.

Reizer, J., Reizer, A. \& Saier, M. H. Jr (1997). Microbiol. 143, 2519-2520.

Sakai, Y., Mitsui, R., Katayama, Y., Yanase, H. \& Kato, N. (1999). FEMS Microbiol. Lett. 176 125-130.

Strøm, T., Ferenci, T. \& Quayle, J. R. (1974). Biochem. J. 144, 465-476.

Watt, C. I. F. (1998). Comprehensive Biological Catalysis: A Mechanistic Reference, edited by M. Sinnott, Vol. 1, pp. 253-272. London: Academic Press.

Yasueda, H., Kawahara, Y. \& Sugimoto, S. (1999). J. Bacteriol. 181, 7154-7160. 